\title{
School Psychology Supervisors' Perceptions of Specialist-Level Training: An Exploratory Study
}

\author{
Heather E. Ormiston ${ }^{1}$ (D) A Abigail L. Dixon ${ }^{1} \cdot$ Amanda Barnett $^{1}$ \\ Accepted: 8 February 2021 / Published online: 12 March 2021 \\ (C) California Association of School Psychologists 2021
}

\begin{abstract}
Surveys of trainers in school psychology have been administered to examine training competencies and content delivered to school psychology trainees. Surveys of practitioners working with school psychology trainees are limited as discussed by Lewis et al. (2005). The purpose of this exploratory study is to seek to understand the perceptions of specialist-level site-based supervisors in relation to practicum students' knowledge in several competency areas. Utilizing the National Association of School Psychologists' Model for Comprehensive and Integrated School Psychological Services and Standards for Graduate Preparation of School Psychologists as reported by NASP (2020b) and commonly reported school psychology practices as discussed by McNamara et al. (2019), a survey was developed and administered to specialist-level practicum supervisors. Results of Chronbach's alpha analyses examining internal consistency for each of the seven domains ranged from good to excellent (0.85-0.95) although mean differences in domain ratings were not found to be significant. Results of the study are presented along with study limitations and directions for future research.
\end{abstract}

Keywords Supervision · Practicum $\cdot$ School psychology training $\cdot$ Practicum student

School psychologists are broadly trained in a variety of domains to support children including legal and ethical practice, consultation, assessment, culturally responsive practice, and evidence-based practices (National Association of School Psychologists (NASP) 2020b). School psychology training programs accredited by the National Association of School Psychologists (NASP) undergo strict evaluation to ensure the training of graduate students adheres to the standards set forth by the accrediting body. Specifically at the specialist level, NASP's Standards for Graduate Preparation of School Psychologists align with the NASP Standards for the Credentialing of School Psychologists and the NASP Model for Comprehensive and Integrated School Psychological Services (NASP, 2020b) to guide training programs' curriculum and training content. NASP's Policies and Procedures for the Review and Accreditation of Graduate Programs in School Psychology (NASP, 2020a) states:

Heather E. Ormiston

ormiston@indiana.edu

1 Department of Counseling and Educational Psychology, Indiana University Bloomington, 201 N. Rose Ave, Bloomington, IN 47405, USA
Program accreditation suggests higher quality of preparation, comprehensive content, extensive and properly supervised field experiences, and the ability of candidates to perform competently and to positively impact children, youth, families, and others they serve. School psychologists graduating from accredited programs will be comprehensively trained to perform a broad based role and prevent and address the behavioral, socialemotional, mental health, and academic challenges in today's schools. (p. 7)

Successfully graduating from a NASP-accredited school psychology program helps the graduate meet the education requirements needed to obtain their Nationally Certified School Psychologist (NCSP) endorsement (Prus \& Strein, 2011), currently recognized by 33 states nationwide (NASP, n.d.).

\section{An Examination of School Psychology Practice and Training}

From a practical standpoint, the activities school-based school psychologists engage in on a daily basis may be narrower in scope than the broad model (NASP, 2020b) in which they 
were trained. Some of this may relate to regional differences and expectations of school psychologists' roles (Hosp \& Reschly, 2002) while some of it may relate to demographic characteristics, resources available to practitioners, and student to school psychologist ratios (McNamara et al., 2019). Such role discrepancies may also be related to the orientation of the training program from which an individual graduates (e.g., a behaviorally oriented program versus an intervention focused program; Hosp \& Reschly, 2002). To better understand the reality of school psychological services and the field overall, NASP administers a survey to a random sample of its members every five years. The survey seeks to gather information related to demographics, job positions and employment settings, and various professional practices (Walcott et al., 2016).

The most recent comprehensive survey administered in 2015 yielded over 1200 responses (McNamara et al., 2019). School psychologists consistently report that conducting psychoeducational evaluations (i.e., assessment and report writing) for special education identification remains a significant portion of their role (McNamara et al., 2019), a trend seen in past surveys (Castillo et al., 2012). Additional surveys in more specific settings, such as early childhood, indicates this trend to be the case as well (Albritton et al., 2019). On the opposite end, the area of program evaluation is arguably an underutilized aspect of school-based practice. McNamara et al. (2019) reported program evaluation was the lowest rated item in the 2015 study; respondents reported "rarely" engaging in these activities.

Consultation has been a long-standing part of school psychology practice (Erchul \& Young, 2014) and continues to remain a common element of school-based practice (McNamara et al., 2019). Despite the need for consultation skills in school psychology, competency in consultation takes a longer time to develop compared to skills such as assessment (Guiney \& Zibulsky, 2017). One suspected reason for this has to do with limited supervision in this domain (Rosenfield, 2013). An individual's self-efficacy in consultation as well as limited opportunities to engage in consultation practices may also hinder the development of such skills (Guiney \& Zibulsky, 2017).

A major focus of NASP in recent years is the emphasis on social justice in school psychology (NASP, 2017). As a component of the NASP Practice Model (2020b), this is an important component of training. However, the demographics of the field have not shifted to reflect the changing population in the United States (McNamara et al., 2019; Newell et al., 2010; Walcott et al., 2016). Additionally, while most school psychologists likely support social justice, the translation of these aspirations into practice may be more limited (Shriberg et al., 2008).

Additional research has examined perceptions of school psychologists' roles from the perspectives of teachers and others working in schools (Farrell et al., 2005; Hagemeier et al., 1998). For instance, a survey of 278 school personnel, including teachers, related mental health professionals (e.g., school counselors), and administrators, reportedly endorsed a desire for school psychologists to assist with developing prereferral interventions, delivering behavioral interventions, and implementing classroom interventions. A majority of the respondents-nearly $90 \%$-indicated wanting school psychologists to engage in activities related to special education placement and other related activities (Hagemeier et al., 1998). Similarly, an international study of teachers from 8 countries found that while assessing students for special education was the most common function of the school psychologist, they desired to see the school psychologist's role expanded to include providing training for teachers, working with families, and providing therapeutic interventions for students (Farrell et al., 2005).

Just as practicing school psychologists are surveyed, so too are graduate programs responsible for the training and preparation of future practitioners. The 2019 NASP Report of Graduate Education in School Psychology: 2017-2018 (Gadke et al., 2019) reports 249 total academic institutions in the United States offer school psychology programs. Based on survey data obtained from the 2017-2018 school year $(n=222), 145$ of the programs available were accredited by NASP. Nineteen programs had conditional accreditation, and 58 programs surveyed were not accredited. Notably, specialist programs offer a wide range of credit hour requirements, ranging from 50 to 104 credit hours, with a mean of 69.9 credit hours required for degree completion. It should be noted that for analysis purposes, Gadke et al. (2019) converted provided metrics into comparable semester hours (e.g., converted quarter hours to semester hours) to ensure commensurate comparison across diverse states and programs. A majority of programs' graduate students go on to successfully gain employment, although it is noted some students $(n=94$ students (73 specialist-level) ) "exited the program due to inadequate performance, and an estimated 330 students withdrew" (Gadke et al., 2019, p. 8). There appears to be promising trends related to total applicants and enrollment into school psychology programs overall (Gadke et al., 2019).

\section{School Psychology Program Accreditation and Training}

NASP accreditation standards require training programs provide coursework and training related to the various aspects of the Practice Model (2020b) and legal and ethical practices, while also specifying requirements for field-based activities (NASP, 2020b). To this latter point, in order to meet the NASP accreditation standards, several recommendations are made for programs that allow for performance-based 
assessment of students' and training programs' competencies (Prus \& Garcia-Vazquez, 2014). These include results of student performance measures from coursework and standardized exams such as the PRAXIS as well as assessment of students during practica and internship (Prus \& GarciaVazquez, 2014; Prus \& Strein, 2011) by field-based supervisors. Specifically, accredited training programs are required to gather evaluations from field-based supervisors in relation to the students' performance in practice-based settings. The purpose of school psychology practica experiences are "fieldbased activities designed to develop and evaluate school psychology candidates' mastery of specific professional skills consistent with program goals" (NASP, 2020b, p. 30) and may reflect specific skills to be developed or a range of skills in development. The practica require "[c]lose supervision by program faculty and qualified practicum supervisors and inclusion of appropriate performance-based evaluation" (NASP, 2020b, p. 32) to ensure students are developing targeted competencies. Typically, this requires evaluation of students by qualified site-based supervisors.

\section{Training Future School Psychologists}

At a time when the field of school psychology is undergoing a severe shortage due to a "graying of the field" (Castillo et al., 2014; Curtis et al., 2004) with practitioners retiring, the field is pressed to train larger numbers of students. Castillo et al. (2014) used data from the NASP 2009-2010 national study to present personnel shortage projections, projected across 5 , 10, and 15 years. At the time of analysis, Castillo et al. (2014) estimated that by the year 2020, there would be 35,225 school psychologists leaving the field, due to both retirement and an estimated 5\% attrition rate for situations such as job transition and personal health concerns. It was estimated that just five years later, the number of psychologists leaving the field would increase to greater than 50,000. In contrast, programs were projected to produce a cumulative total of 22,980 new school psychology graduates by 2020 and 34,470 by the year 2025. According to these statistics, the field would see a projected deficit of 1225 school psychologists per year, although there is a glimmer of hope that school psychology training programs are seeing an increase in enrollment (Gadke et al., 2019). Despite the increase in enrollment as of late, the need for school psychologists appears to be much greater than the rates at which school psychologists are entering the field.

Nearly 30 years ago, Gutkin and Conoley (1990) indicated a historical disconnect between school psychology training and practice. Although surveys have been administered to determine the landscape of school psychology training and practice since then (e.g., Anton-LaHart \& Rosenfield, 2004; Rogers et al., 1992; Shernoff et al., 2003; Walker et al., 1999;
Wilson \& Reschly, 1996), many of these surveys were only administered to training programs thereby neglecting the perspective of site-based supervisors. The exception may be in relation to a study conducted in 2005. Lewis et al. (2005) conducted a survey of 263 practicum site coordinators at the predoctoral level. Results indicated site supervisor concerns regarding communication between graduate training programs and practicum site coordinators in relation to the sites' awareness of expectations set forth by the training program. What appears to be lacking is not only a recent survey, but one that seeks to collect feedback not from training programs themselves, but from the individuals in the field that witness the actual implementation of training into practice: site-based supervisors and practitioners.

\section{Present Study}

The purpose of our exploratory study is to seek to understand the perceptions of site-based supervisors to determine if training programs are preparing students for the field. In other words, the present exploratory study sought to better understand supervisors' perceptions of school psychology practicum students' level of knowledge in relation to various training competencies. The study gathered information from supervisors working with specialist-level practicum students. The following research question guided the present study: What are the perceptions of school-based practicum supervisors in relation to specialist-level students' training competencies?

\section{Methods}

\section{Survey}

The survey was reviewed by two experts in the field and feedback was provided regarding content and administration. The reviewers suggested reducing the number of items in an attempt to reduce administration time. Thus, the number of overall topics in the survey was reduced and the number of sub-items within each topic was also reduced. The original survey went from 30 items (including demographic questions and open-ended responses) and 44 sub-items to 23 items (including demographic questions and open-ended responses) and 32 sub-items. Additional feedback recommended the survey instructions be modified to clarify the level of respondent the survey was seeking. The survey sought responses from supervisors who could reflect on the "typical" specialistlevel school psychology practicum students/externs they supervised in the last 3 years. An additional note was added to clarify the meaning of "specialist-level," defined as students 
enrolled in master's level/CAGS/EdS degree programs, excluding students enrolled in doctoral-level programs.

The principal investigator asked survey participants to complete the 23-item online survey. Survey questions were developed using the NASP Practice Model (NASP, 2020b) while also incorporating aspects of practice most commonly engaged in by specialist-level psychologists (e.g., assessment and report writing; Castillo et al., 2012; McNamara et al., 2019) and standards of professional practice and graduate training (NASP, 2020b). For the sake of brevity, and at the expert reviewers' suggestion, aspects of practice that are rarely utilized (e.g., program evaluation; McNamara et al., 2019) were omitted. The questions asked participants to rate their school psychology students' knowledge in relation to various school psychology areas of practice (e.g., assessment, report writing, family-school collaboration, etc.). The Likert scale questions asked participants to rate their agreement to the item, along with an option to offer additional comments at the end of each topic of questions. While some demographic information was collected (e.g., position, school corporation locale, gender, degree level, school demographics, years in practice, etc.), no specific identifying information was obtained (e.g., name, school or school district name).

The survey included seven demographic items and seven domains of topical content. Participants were asked to rate their agreement on items related to competency areas along a 5-point Likert scale ranging from Not at all Knowledgeable (1) to Very Knowledgeable (5). The domains addressed assessment, report writing, law and ethics, evidence-based practices, collaboration and consultation, professionalism, and diversity. The number of sub-items in each domain varied from 3 to 8 items. After each of the domains' sub-items, participants could record open-ended comments. Questions were provided via a stem such as "To what extent do students demonstrate knowledge of..." and then a suffix such as, "...conducting a Functional Behavior Assessment?" under the Assessment domain or "...data analysis to interpret results of intervention implementation?" in the Evidence-Based Practices domain.

\section{Participant Demographics}

The survey was administered using Qualtrics. Thirty-three participants opened the survey, and thirty-two provided consent. A total of 29 surveys were fully completed, and those completed surveys were used for this exploratory study. A majority of participants were employed by a school district/ cooperative; only one participant endorsed working in the private practice setting. All levels of practice were represented: preschool $(n=16)$; primary (grades $\mathrm{K}-2 ; n=23)$; intermediate (grades $3-5 ; \mathrm{n}=22$ ); middle school (grades 6-8; $n=14$ ); and high school (grades 9-12; $n=14$ ). Using definitions provided by the National Center for Education Statistics (n.d.), participants represented all locales: city/urban (27.5\%), suburban (38\%), rural (27.5\%), and town (7\%). Participants also worked in the field for varied lengths of time: 0-3 years (10\%); 4-6 years (28\%), 7-10 years (17\%), 11-15 years $(21 \%)$, $16-20$ years $(10 \%)$, and $20+$ years (14\%). Most had degrees at the specialist/CAGS level (80\%), while master's level and doctoral level were equally represented (10\% each). A total of $93 \%$ of the sample identified as female, and $7 \%$ identified as male; $66 \%$ of respondents were currently supervising students, and $34 \%$ of the sample had supervised students in the past. The number of students supervised ranged from 1 to 8 , and the mean number of students supervised was $2.84(S D=$ 1.97). Students in their second year were most commonly supervised (second year, first semester $=35 \%$; second year, second semester $=38 \%$; second year, summer $=4.8 \%$ ) while some first year students were also supervised (first year, first semester $=9.5 \%$; first year, second semester $=8 \%$; other $=$ $4.8 \%)$.

\section{Procedures}

This study served as an exploratory study seeking to survey school psychology field-based practicum supervisors. Participants were recruited utilizing a snowball method of data collection. A link to the survey was posted to several school psychology Facebook pages with permission from the page hosts. The Facebook pages were user-generated, meaning they were developed by practicing school psychologists for practicing school psychologists. The pages are "private" and require a user to "request" access to the page. Posting the survey on these sites also allowed participants to "share" the survey, meaning the survey could then be shared on a personal Facebook page. The survey remained open from February 2, 2020 through February 16, 2020 with one reminder posted. Identifying information was not collected.

\section{Compliance with Ethical Standards}

Informed consent was obtained online prior to participants gaining access to the online survey. All procedures adhered to and complied with all standards and requirements of the university's Institutional Review Board for the protection of human subjects. This was an unfunded study and the authors do not disclose any financial conflicts as part of this study.

\section{Results}

\section{Survey Domains}

Table 1 presents internal consistency coefficients for each of the seven domains. Chronbach's alpha coefficients all ranged from good to excellent (0.85-0.95). Descriptive statistics for the seven domains are also provided in Table 1. Mean 
Table 1 Internal consistency (Cronbach's alpha) and descriptive statistics for each domain

\begin{tabular}{lllll}
\hline Domain & No. of items & Chronbach's alpha & $M$ & $S D$ \\
\hline Assessment Practices & 8 & 0.93 & 2.69 & 0.87 \\
Report Writing & 3 & 0.91 & 3.12 & 1.13 \\
Law and Ethics & 3 & 0.85 & 2.99 & 0.98 \\
Evidence-Based Practices & 7 & 0.95 & 2.67 & 1.03 \\
Collaboration and Consultation & 3 & 0.93 & 3.25 & 1.11 \\
Professionalism & 3 & 0.87 & 3.14 & 0.99 \\
Cultural Diversity & 3 & 0.91 & 2.93 & 1.09 \\
\hline
\end{tabular}

comparisons between domains did not yield statistically significant results.

\section{Survey Items}

\section{Assessment}

The section of the survey examining assessment practices contained 8 sub-items. The internal consistency of this domain was excellent (Chronbach's alpha $=0.93$ ). The highest rated item in this category addressed students' knowledge of a variety of cognitive assessments $(M=$ $3.19, S D=0.92$ ). The lowest rated area was in relation to students' knowledge about conducting Functional Behavior Assessments (FBAs; $M=2.22, S D=$ 1.09).Supervisors rated students' depth of understanding of academic assessments $(M=2.85, S D=1.13)$, knowledge of various behavior rating scales $(M=2.89, S D=$ 0.93 ), and knowledge of various observation techniques (e.g., $\mathrm{ABC}$ observations, momentary-time sampling; $M=$ $2.78, S D=1.12)$ similarly. Knowledge of various adaptive behavioral rating scales $(M=2.37, S D=1.00)$, how to select an appropriate battery of assessments based upon referral questions $(M=2.63, S D=1.19)$, and knowledge of clinical interviewing skills $(M=2.56, S D=1.05)$ were on the lower end of endorsed knowledge ratings.
Differences between item means within this domain were not found to be statistically significant. See Table 2 for a summary of results.

\section{Report Writing}

Within this domain, students were rated the highest for overall writing skills (grammar, punctuation, etc.; $M=3.40, S D=$ 1.29; see Table 3). Knowledge of how to write an integrated report that interprets developmental and social history, interview, and assessment results was rated next highest $(M=3.04$, $S D=1.06)$. Writing for a professional audience (e.g., parents, teachers) was the lowest rating $(M=2.92, S D=1.32)$ in this domain. Differences between item means within this domain were not found to be statistically significant. The internal consistency of this domain was found to be excellent $($ Chronbach's alpha $=0.91)$.

\section{Law and Ethics}

Supervisors' ratings of students' knowledge of law and ethics were rated similarly within this domain (see Table 4). The highest rated item was related to students' knowledge of NASP ethical standards $(M=3.16, S D=1.06)$ while ratings of how to incorporate ethical standards into daily practice ( $M$ $=2.96, S D=1.14)$ and state special education law $(M=2.83$,

Table 2 Assessment Practices domain mean ratings

\begin{tabular}{|c|c|c|}
\hline Item & $M$ & $S D$ \\
\hline a variety of cognitive assessments? & 3.19 & 0.92 \\
\hline depth of understanding of various academic assessments? & 2.85 & 1.13 \\
\hline depth of understanding of various behavioral rating scales? & 2.89 & 0.93 \\
\hline various adaptive behavior rating scales? & 2.37 & 1.00 \\
\hline clinical interviewing skills? & 2.56 & 1.05 \\
\hline various behavioral observation techniques (e.g., $\mathrm{ABC}$ observation, momentary-time sampling, etc.)? & 2.78 & 1.12 \\
\hline how to select the appropriate battery of assessments based upon referral question? & 2.63 & 1.19 \\
\hline conducting a Functional Behavior Assessment? & 2.22 & 1.09 \\
\hline
\end{tabular}


Table 3 Report Writing domain mean ratings

\begin{tabular}{lr}
\hline Item & SD \\
\hline writing an integrated report that interprets developmental and social history, interview, and assessment results? & 3.04 \\
writing for a professional audience (e.g., parents, teachers, etc.)? & 2.92 \\
writing skills overall (e.g., grammar, punctuation, coherent thoughts, etc.)? & 1.06 \\
\hline
\end{tabular}

$S D=1.17$ ) were similarly rated slightly lower. Differences between item means within this domain were not found to be statistically significant and the internal consistency of this domain was good (Chronbach's alpha $=0.85$ ).

\section{Evidence-Based Practices}

All scores in this domain were rated similarly (see Table 5). Students' understanding of the multi-tiered continuum of services was rated highest in this domain $(M=2.84, S D=1.18)$. Two items had identical mean scores in terms of the lowest ratings: knowledge of data analysis to interpret results of intervention implementation $(M=2.56, S D=1.23)$ and knowledge regarding how to successfully execute school-based socioemotional interventions and supports $(M=2.56, S D=$ 1.00). Other items in this domain included knowledge of planning interventions based upon the referral question $(M=2.72$, $S D=1.10)$, how to identify an evidence-based practice $(M=$ 2.72, $S D=1.31)$, the Response to Intervention framework ( $M$ $=2.68, S D=1.26$ ), and how to successfully implement a manualized socioemotional or academic curriculum (e.g., Second Step, Coping Cat; $M=2.60, S D=1.12$ ). Differences between item means within this domain were not found to be statistically significant. The internal consistency of this domain was excellent (Chronbach's alpha $=0.95)$.

\section{Collaboration and Consultation}

The highest mean rating in this domain, and indeed on the whole survey, was students' knowledge of how to effectively build relationships and communicate with students $(M=3.58$, $S D=1.06$; see Table 6). Knowledge related to how to effectively build relationships and communicate with school personnel $(M=3.13, S D=1.15)$ and how to effectively build relationships and communicate with families $(M=3.04, S D=$

Table 4 Law and Ethics domain mean ratings

\begin{tabular}{lll}
\hline Item & $M$ & $S D$ \\
\hline state special education law? & 2.83 & 1.17 \\
NASP ethical standards? & 3.16 & 1.06 \\
how to incorporate ethical standards into daily practice? & 2.96 & 1.14 \\
\hline
\end{tabular}

1.33) were similarly rated. Differences between item means within this domain were not found to be statistically significant while the internal consistency of this domain was excellent (Chronbach's alpha $=0.93)$.

\section{Professionalism}

The highest rating in this domain was students' knowledge concerning seeking supervision as needed when situations arise $(M=3.43, S D=1.20$; see Table 7$)$. The lowest rating was students' knowledge of how to identify limitations in their skill set $(M=2.96, S D=1.15)$. Students' knowledge about how to advocate for their own personal needs $(M=3.04, S D=$ 0.98) was rated slightly higher. Differences between item means within this domain were not found to be statistically significant. The internal consistency of this domain was good (Chronbach's alpha $=0.87$ ).

\section{Diversity}

The highest mean rating in this domain was supervisors' ratings of students' commitment to issues of social justice ( $M=$ 3.04, $S D=1.22$; see Table 8). Similarly rated was students' understanding that their cultural background influences their interactions with students, teachers, and families $(M=3.00$, $S D=1.17)$. The lowest rating in this area related students' global knowledge to an understanding of cultural and linguistic differences $(M=2.74, S D=1.18)$. The internal consistency of this domain was excellent (Chronbach's alpha $=0.91$ ) although significant differences between mean ratings were not found.

\section{Discussion}

While engaging in supervisory practices of students in training is not common (McNamara et al., 2019), and in fact engaging in the supervision of others, including students, is not required of NASP to be credentialed in school psychology (NASP, 2020b), it serves as a critically important aspect of student training. Supervision provides guidance and feedback with the intention of supporting an individual's growth and ultimately improving one's practice (Guiney, 2019; NASP, 2020b). Just as there are responsibilities a supervisor must 
Table 5 Evidence-Based Practices domain mean ratings

\begin{tabular}{lrr}
\hline Item & $S D$ \\
\hline planning interventions based upon referral question? & 2.72 & 1.10 \\
data analysis to interpret results of intervention implementation? & 2.56 & 1.23 \\
the Response to Intervention framework (rationale, process, etc.)? & 1.26 \\
how to successfully execute school-based socioemotional interventions and supports? & 2.68 & 2.56 \\
how to successfully implement a manualized socioemotional or academic curriculum (e.g., Second Step, Coping Cat)? & 2.60 & 1.00 \\
an understanding of the multi-tiered continuum of services? & 1.12 \\
how to identify an evidence-based practice? & 1.18 \\
\hline
\end{tabular}

take on in this area (e.g., monitoring the supervisee's tasks, modeling ethical practice, supervising within areas of competence), so too must a supervisee take on certain responsibilities such as being open to receiving feedback and asking questions as needed (Guiney, 2019).

Supervisors are responsible for providing frequent and constructive feedback regarding a supervisee's practice (Guiney, 2019). The present survey asked supervisors to reflect on multiple, yet commonly seen, areas of practice engaged in by specialist-level practicum students. The adequate internal consistency of the survey itself indicates it appears to be a reliable tool to gather supervisors' perspectives on students' competencies. Although statistically significant differences in mean scores across and within domains were not found, there were trends in the data that can be examined more closely.

First, although not statistically significantly different from other domains, the domain mean for Collaboration and Consultation was the highest. The items in this domain reflected a student's interpersonal skills. The lowest domain mean, although not significantly different from others, was the Evidence-Based Practices domain. Items of lowest mean rating in the Evidence-Based Practices domain related to analyzing intervention outcome data and successfully executing socioemotional interventions. Although student training related to evidence-based practices is a domain of importance (Kratochwill, 2007), especially when it comes to the identification of learning disabilities under the Response to Intervention (RtI) model (U.S. Department of Education, 2004), school psychologists are not engaging in these practices regularly (McNamara et al., 2019).

Considering the frequency in which school psychologists are engaged in psychoeducational evaluations (McNamara et al., 2019), which involve not only assessment but also report writing, this is an important aspect of training competence to examine. Items in the Assessment domain tended to be rated lower relative to items in other domains while Report Writing tended to be on the higher end. Although not statistically significant, the lowest overall item mean rating in the Assessment domain was knowledge related to conducting functional behavior assessments. This finding is consistent with previous research that has consistently demonstrated educators continue to struggle to conduct effective FBAs (Blood \& Neel, 2007; Borgmeier et al., 2015; Van Acker et al., 2005). Psychoeducational reports tend to be written in a manner that is too technical and not easily understood by parents and teachers (Lichtenstein, 2013). Thus, items in the Report Writing domain examined students' abilities to write a coherent, grammatically correct, integrated report for a professional audience, and seemed to have ratings that were a bit higher compared to other domains, although no significant difference was found.

The second highest domain rating, although not statistically significant, was in Professionalism. Competencies related to legal and ethical knowledge, within the Legal and Ethics domain, including knowledge of local special education laws, ethical practice, and incorporating such knowledge into practice, had a domain mean rating that was in the middle of all domains assessed. Professional practice, legal, and ethical skills and knowledge all fall under the Legal, Ethnical, and Professional Practice domain of the NASP Standards for Graduate Preparation of School Psychologists (2020b). These practices are also a heavy emphasis in the NASP Practice Model (NASP, 2020b) and should be integrated throughout coursework in the training program to maximize
Table 6 Collaboration and Consultation domain mean ratings

\begin{tabular}{llr}
\hline Item & M & \multirow{2}{*}{$S D$} \\
\hline how to effectively build relationships and communicate with students? & 3.58 & 1.06 \\
how to effectively build relationships and communicate with school personnel? & 3.13 & 1.15 \\
how to effectively build relationships and communicate with families? & 3.04 & 1.33 \\
\hline
\end{tabular}


Table 7 Professionalism domain mean ratings

\begin{tabular}{lll}
\hline Item & $M$ & $S D$ \\
\hline how to identify limitations in their skill set? & 2.96 & 1.15 \\
how to advocate for their own personal needs? & 3.04 & 0.98 \\
seeking supervision as needed when situations arise? & 3.43 & 1.20 \\
\hline
\end{tabular}

learning (Boccio, 2015) and ensure program graduates are well prepared to engage in legal and ethical practice upon entering the field.

Interestingly, the Cultural Diversity domain mean also tended to be lower, although a significant difference was not found. The NASP Practice Model (2020b) emphasizes the importance of training in relation to cultural competency.NASP has also emphasized the importance of culturally responsive practice (Miranda, 2014) and social justice scholarship and advocacy (NASP, 2017; Shriberg et al., 2011). However, practicum supervisors are indicating this is an aspect of competency that may need to be strengthened. Becoming culturally competent is an intensive process (Miranda, 2014), and there has been a documented need to adequately include multicultural content into training program content (Newell et al., 2010). These results may demonstrate that while many individuals often endorse social justice practices (Shriberg et al., 2011), individuals "may have not yet made the connection between social justice as an aspirational goal and the process of critical self and societal exploration commonly identified as vital steps toward achieving this goal" (Shriberg et al., 2011, p. 50).

In light of current exploratory survey results, a few interpretations are possible. On one hand, it is possible supervisor expectations are not in alignment with developmentally appropriate levels of competence (Guiney, 2018). Despite the requirement of receiving supervision as part of the NASP Standards for Graduate Preparation of School Psychologists (2020b), few students actually receive specific training on how to be a supervisor as part of their graduate coursework (Ross \& Goh, 1993; Silva et al., 2016; Zins et al., 1989). For instance, a recent study of 700 early career school psychologists conducted by Silva and colleagues found a majority did not receive any type of training in how to be a supervisor. Only $29 \%$ of the sample in the Silva et al.,
(2016) study reported currently receiving any type of professional supervision, reflecting the critical importance of receiving supportive and formative supervision during the training phase. Thus, the relationship between training programs and field-based supervisors should not be minimized. Guiney (2019) highlights the mutually beneficial and "symbiotic relationship" (p. 161) between the two. Historically, there was a disconnect (Gutkin \& Conoley, 1990) between training programs' views of competency and supervisors' views of competency, speaking to the need to have consistent and ongoing communication with site-based supervisors (Guiney, 2018). Further research garnering perspectives of both supervisors and training programs in relation to students' competencies is warranted to further examine if this disconnect is still present.

Still another interpretation of the results could point to the potential disconnect between training in NASP-approved programs and actual school-based practice. Tarquin and Truscott (2006) surveyed practicum students and found that although students were trained in a variety of roles and practices consistent with the NASP Domains of Practice (2020b), students were reporting practicum experiences that did not align with these innovative practices and such practices were not modeled by their supervisors.

\section{Limitations and Directions for Future Research}

The researchers identified several limitations of the study including the use of a convenience sample, a small sample size ( $n=29$ completed surveys), and a focus on specialist-level practicum students only. Additionally, specific demographic information such as supervisor's geographic location (e.g., Midwest) and ethnicity was not collected, thereby limiting the ability to generalize the results based on these characteristics. Another limitation of the study relates to some of the specific survey items being limited in the breadth of their scope. For instance, the items in the Consultation and Collaboration domain focused solely on students' interpersonal skills rather than also including skills such as problemsolving and/or measuring a consultant's effectiveness (Guiney \& Zibulsky, 2017).

Table 8 Cultural Diversity domain mean ratings

\begin{tabular}{lr}
\hline Item & SD \\
\hline an understanding of cultural and linguistic differences? & 1.18 \\
an understanding that their cultural background influences their interactions with students, teachers, and families? & 3.74 \\
a commitment to issues of social justice? & 1.17 \\
\hline
\end{tabular}


This exploratory survey and its outcomes lead to several directions of future research. First, a survey of this focus, while expanding the content to include a broader depth of training, should be administered on a larger scale to gather more representative perspectives of students' training competencies. Similarly, a large-scale survey can be conducted not just of specialist-level practicum students, but of specialistlevel interns as well. It is possible, indeed likely, that a majority of growth and training takes place while on internship, and by the time students complete their training requirements, they have developed into highly competent school psychologists.

Additionally, the field may be well served to examine differences in competency ratings between school-based doctoral students versus specialist-level students, and we recommend expanding the items to include doctoral-level practicum students as well as specialist-level and doctoral-level interns practicing in the schools. An analysis of this capacity could allow researchers to examine how practicum ratings relate to intern ratings.

Finally, surveying graduate students themselves would be beneficial to examine trainees' own perceptions of competence in relation to supervisor perceptions and field-based practice. A study of this nature was previously conducted (Tarquin \& Truscott, 2006), and warrants replication. An extension of this also involves examining the perceptions of training programs to see how perceptions of students' competencies as a training program align with the ratings of supervisors in the field. Triangulating data between practicum and/ or internship supervisors, employers (post-degree), and training directors may be warranted.

\section{Conclusion}

Only a handful of surveys have been administered to determine the landscape of school psychology training and practice (e.g., Anton-LaHart \& Rosenfield, 2004; Rogers et al., 1992; Shernoff et al., 2003; Walker et al., 1999; Wilson \& Reschly, 1996), and many of these surveys were administered only to training programs. As a result, the perceptions of supervisors were not obtained. While more and more resources are becoming available to support supervisors in their training of practicum students (e.g., The School Psychology Supervisor's Toolkit by Guiney, 2019; Supervising the School Psychology Practicum by Kelly \& Davis, 2016), and NASP requires collaboration between university-level and field-based supervisors to solicit feedback on individual student performance, there appears to be little systematic guidance in terms of integrating the feedback into training practices. We encourage the field to be more systematic in collecting broad perceptions of supervisors at the practicum and internship training levels, as well as at the specialist and doctoral levels. We also encourage programs to regularly administer surveys to supervisors gathering feedback on knowledge and training of students that have been placed with them — not just individually — particularly for supervisors that have long-standing collaborations with training programs. For instance, gathering perspectives related to trends supervisors have noticed in terms of whether training practices have adhered to the changing field or whether supervisors notice consistent aspects of practice that tend to be weak in students placed at their site could be beneficial. Taking these steps can continue to strengthen not only the relationships between training programs and supervisors but also the school psychologist trainees entering this demanding field.

\section{Declarations}

Informed consent Informed consent was obtained online prior to participants gaining access to the online survey. All procedures adhered to and complied with all standards and requirements of the university's Institutional Review Board for the protection of human subjects. This was an unfunded study and the authors do not disclose any financial conflicts as part of this study.

\section{References}

Albritton, K., Mathews, R. E., \& Boyle, S. G. (2019). Is the role of the school psychologist in early childhood truly expanding? A national survey examining school psychologists' practices and training experiences. Journal of Applied School Psychology, 35(1), 1-19.

Anton-LaHart, J., \& Rosenfield, S. (2004). A survey of preservice consultation training in school psychology programs. Journal of Educational and Psychological Consultation, 15(1), 41-62.

Blood, E., \& Neel, R. S. (2007). From FBA to implementation: A look at what is actually being delivered. Education and Treatment of Children, 30(4), 67-80.

Boccio, D. E. (2015). A brief guide to teaching professional ethics in a graduate preparation program [Ethics advisory bulletin]. Bethesda, MD: National Association of School Psychologists.

Borgmeier, C., Loman, S. L., Hara, M., \& Rodriguez, B. J. (2015). Training school personnel to identify interventions based on functional behavioral assessment. Journal of Emotional and Behavioral Disorders, 23(2), 78-89.

Castillo, J. M., Curtis, M. J., \& Gelley, C. (2012). School psychology 2010 -Part 2: School psychologists' professional practices and implications for the field. Communiqué, 40, 8.

Castillo, J. M., Curtis, M. J., \& Tan, S. Y. (2014). Personnel needs in school psychology: A 10-year follow up study on predicted personnel shortages. Psychology in the Schools, 51, 832-849.

Curtis, M. J., Chesno Grier, J. E., \& Hunley, S. A. (2004). The changing face of school psychology: Trends in data and projections for the future. School Psychology Review, 33, 49-66.

Erchul, W. P., \& Young, H. L. (2014). Best practices in school consultation. In P. L. Harrison \& A. Thomas (Eds.). Best practices in school psychology V. Bethesda, MD: National Association of School Psychologists.

Farrell, P., Jimerson, S., Kalambouka, A., \& Benoit, J. (2005). Teachers' perceptions of school psychologists in different countries. School Psychology International, 26(5), 525-544.

Gadke, D. L., Valley-Gray, S., \& Rossen, E. (2019). NASP report of graduate education in school psychology: 2017-2018 [Research 
report]. Bethesda, MD: National Association of School Psychologists.

Guiney, M. C. (2018). Addressing problems of professional competence: Collaborating with university training programs to support struggling supervisees. Communiqué, 46(6), 6-7.

Guiney, M. C. (2019). The school psychology supervisor's toolkit. New York, NY: Routledge.

Guiney, M. C., \& Zibulsky, J. (2017). Competent consultation: Developing self-efficacy for process and problem aspects of consultation. Journal of Educational and Psychological Consultation, 27(1), 52-71.

Gutkin, T. B., \& Conoley, J. C. (1990). Reconceptualizing school psychology from a service delivery perspective: Implications for practice, training, and research. Journal of School Psychology, 28, 203223.

Hagemeier, C., Bischoff, L., Jacobs, J., \& Osmon, W. (1998). Role perceptions of the school psychologist by school personnel. National Association of School Psychologists Annual Convention. FL: Orlando.

Hosp, J. L., \& Reschly, D. J. (2002). Regional differences in school psychology practice. School Psychology Review, 31, 11-29.

Kelly, K.K., \& Davis, S. D. (2016). Supervising the school psychology practicum: A guide for field and unviersity supervisors. New York: Springer.

Kratochwill, T. R. (2007). Preparing psychologists for evidence-based school practice: Lessons learned and challenges ahead. American Psychologist, 62, 826-843.

Lewis, B. L., Hatcher, R. L., \& Pate III, W. E. (2005). The practicum experience: A survey of practicum site coordinators. Professional Psychology: Research and Practice, 36(3), 291-298.

Lichtenstein, R. (2013). Writing psychoeducational reports that matter: A consumer-responsive approach. Communiqué, 42(3).

McNamara, K. M., Walcott, C. M., \& Hyson, D. (2019). Results from the NASP 2015 Membership Survey, Part two: Professional practices in school psychology [Research report]. Bethesda, MD: National Association of School Psychologists.

Miranda, A. H. (2014). Best practices in increasing cross-cultural competency. In P. L. Harrison \& A. Thomas (Eds.), Best practices in school psychology V. National Association of School Psychologists: Bethesda, MD.

National Association of School Psychologists. (2017). Strategic plan: 2017-2022. Bethesda, MD: Author.

National Association of School Psychologists. (2020a). Policies and procedures for the review and accreditation of graduate programs in school psychology. Bethesda, MD: Author.

National Association of School Psychologists. (2020b). The professional standards of the National Association of School Psychologists. Bethesda, MD: Author.

National Association of School Psychologists. (n.d.). Why become an NCSP? Retrieved from https://www.nasponline.org/standards-andcertification/national-certification/why-become-an-ncsp

National Center for Education Statistics. (n.d.). Locale classifications and criteria. Retrieved from https://nces.ed.gov/programs/edge/docs/ LOCALE DEFINITIONS.pdf

Newell, M. L., Nastasi, B. K., Hatzichristou, C., Jones, J. M., Schanding, G. T., \& Yetter, G. (2010). Evidence on multicultural training in school psychology: Recommendations for future directions. School Psychology Quarterly, 25(4), 249-278.
Prus, J. S., \& Garcia-Vazquez, E. (2014). Best practices in assessing performance in school psychology graduate programs. In P. L. Harrison \& A. Thomas (Eds.), Best practices in school psychology $V$. National Association of School Psychologists: Bethesda, MD.

Prus, J. S., \& Strein, W. (2011). Issues and trends in the accreditation of school psychology programs in the United States. Psychology in the Schools, 48, 887-900.

Rogers, M. R., Ponterotto, J. G., Conoley, J. C., \& Wiese, M. J. (1992). Multicultural training in school psychology: A national survey. School Psychology Review, 21(4), 603-616.

Rosenfield, S. (2013). Consultation in the schools-Are we there yet? Consulting Psychology Journal: Practice and Research, 65(4), 303-308.

Ross, R. P., \& Goh, D. S. (1993). Participating in supervision in school psychology: A national survey of training and practices. School Psychology Review, 22, 63-80.

Shernoff, E. S., Kratochwill, T. R., \& Stoiber, K. C. (2003). Training in evidence-based interventions (EBIs): What are school psychology programs teaching? Journal of School Psychology, 41, 467-483.

Shriberg, D., Bonner, M., Sarr, B. J., Walker, A. M., Hyland, M., \& Chester, C. (2008). Social justice through a school psychology lens: Definition and applications. School Psychology Review, 37(4), 453468.

Shriberg, D., Wynne, M. E., Briggs, A., Bartucci, G., \& Lombardo, A. C. (2011). School psychologists' perspectives on social justice. School Psychology Forum: Research in Practice, 5(2), 37-53.

Silva, A. E., Newman, D. S., Guiney, M. C., Valley-Gray, S., \& Barrett, C. A. (2016). Supervision and mentoring for early career psychologists: Availability, access, structure, and implications. Psychology in the Schools, 53(5), 502-516.

Tarquin, K. M., \& Truscott, S. D. (2006). School psychology students' perceptions of their practicum experiences. Psychology in the Schools, 43(6), 727-736.

U.S. Department of Education. (2004). Individuals with Disabilities Improvement Act of 2004, Pub. L. 108-466. Federal Register, 70, 35802-35803.

Van Acker, R., Boreson, L., Gable, R. A., \& Potterton, T. (2005). Are we on the right course? Lessons learned about current FBA/BIP practices in school. Journal of Behavioral Education, 14(1), 35-56.

Walcott, C. M., Charvat, J., McNamara, K. M., \& Hyson, D. M. (2016). School psychology at a glance: 2015. In member survey results. National Association of School Psychologists Annual Convention. LA: New Orleans.

Walker, N. W., Stuart Boling, M., \& Cobb, H. (1999). Training of school psychologists in neuropsychology and brain injury: Results of a national survey of training programs. Child Neuropsychology, 5(2), 137-142.

Wilson, M. S., \& Reschly, D. J. (1996). Assessment in school psychology training and practice. School Psychology Review, 25(1), 9-23.

Zins, J. E., Murphy, J. J., \& Wess, B. P. (1989). Supervision in school psychology: Current practices and congruence with professional standards. School Psychology Review, 18, 56-63.

Publisher's Note Springer Nature remains neutral with regard to jurisdictional claims in published maps and institutional affiliations. 
Heather E. Ormiston is a Clinical Assistant Faculty member in the School Psychology program at Indiana University Bloomington. She is the Director of the Child Assessment and Intervention Clinic and coordinates the program's practica and special-level internships. Her research interests include trauma-informed multi-tiered systems of supports, compassion fatigue in teachers and school psychologists, and social justice.

Abigail L. Dixon obtained her Education Specialist degree in School Psychology from Indiana University Bloomington in 2020. She is currently a school psychologist in the Richland-Bean Blossom Community School Corporation working on the Trauma-Informed Multi-Tiered
Systems of support (TIMS) Grant in Ellettsville, Indiana. Mrs. Dixon's focus is to assist the grant team in setting up their MTSS social and emotional learning (SEL) process and provide SEL support to students in the district. Her research interests are in autism spectrum disorder and supporting students with disabilities in inclusion classrooms.

Amanda Barnett obtained her Education Specialist degree in School Psychology from Indiana University Bloomington in 2020. She is currently a school psychologist in the Hamilton-Boone-Madison Special Services Cooperative within the Noblesville School District in Noblesville, Indiana. 